\title{
Geochemical features of organic-rich sediments in the modern ocean
}

\author{
MOEI YANO ${ }^{1}$, KAZUTAKA YASUKAWA $^{1,3}$, \\ KENTARO NAKAMURA ${ }^{1}$, MINORU IKEHARA ${ }^{2}$, \\ YASUHIRO KATO ${ }^{1,3}$ \\ ${ }^{1}$ The University of Tokyo, Tokyo, 113-8656, Japan \\ (m.yano@egeo.t.u-tokyo.ac.jp) \\ ${ }^{2}$ Kochi University, Kochi, 783-8502, Japan \\ ${ }^{3}$ Chiba Institute of Technology, Chiba, 275-0016, Japan \\ (*Corresponding: ykato@sys.t.u-tokyo.ac.jp )
}

In the Phanerozoic eon, reducing ocean depleting dissolved oxygen had emerged repeatedly. As a record of such a reducing ocean environment, sedimentary rocks called black shale with high organic carbon contents and laminations had been formed due to suppressed decomposition of organic matter and activities of benthic organisms. It is well known that black shales are rich in redox-sensitive elements such as V, Mo and Re that are stable as insoluble solid phases in reductive conditions $[1,2]$.

In contrast to large-scale anoxic events in geological past, the modern ocean is enriched in oxygen from the surface to the deep owing to a vigorous overturning circulation. However, anoxic water mass develops in a limited number of sea areas such as restricted basins and high productivity zones. Organic-rich sediments distributed in such areas also show high concentrations of redox-sensitive elements [3,4]. Geochemical characterization of such organic-rich sediments can provide a key to understand physicochemical processes in reducing oceans of deep past including the Cretaceous OAEs and the Permo-Triassic boundary.

In this study, we examined organic-rich sediments collected from core samples drilled by the Deep Sea Drilling Project/Ocean Drilling Program/Integrated Ocean Drilling Program in multiple sea areas where anoxic water mass develops, and analyzed their bulk chemical composition (major and trace element, total organic carbon, and total sulfur contents). We will present geochemical characteristics of the organic-rich sediments and discuss their relationship to sedimentary environments and concentration mechanism(s) of redox sensitive elements.

[1] Brumsack, 2006, Palaeogeogr. Palaeoclimatol. Palaeoecol., 232, 344-361. [2] Cohen et al., 1999, Earth Planet. Sci. Lett., 167, 159-173. [3] Hirst, 1974, Black Sea geology, chemistry, and biology, American Association of Petroleum Geologists. [4] Ravizza et al., 1991, Geochim. Cosmochim. Acta., 55, 3741-3752. 